\title{
Biological complexity behind plankton system functioning: Synthesis and perspectives from a marine Long Term Ecological Research
}

\author{
Domenico D'Alelio* \\ Stazione Zoologica Anton Dohrn, Villa Comunale, 80121 Naples, Italy \\ *Corresponding author: dom.dalelio@gmail.com
}

\begin{abstract}
The functioning of natural communities is the cumulative outcome of multifaceted and intersecting ecological and evolutionary processes occurring at species level. Species are not stable entities but evolve in consequence of contingent factors including the relationships they establish with the environment and other co-occurring species. Studying ecosystems with an eco-evo approach, i.e., by explicitly considering species evolution and interactions, is thus an essential step to envisioning community adaptation to environmental changes. Such an approach would be particularly suitable for studying plankton, a community of both rapidly evolving and strongly interconnected species. In this context, Long Term Ecological Research studies (LTER) allow investigating nature at different levels of complexity, from species to ecosystems. Herein, I examine the most recent results coming from the three-decades plankton LTER 'MareChiara' (LTER-MC) in the Gulf of Naples (Mediterranean Sea, Italy) and discuss their suitability in deepening knowledge on: i) evolutionary bases to plankton diversity (i.e., the founding property of both species and community adaptive potential); ii) ecological and evolutionary determinants of population and community dynamics; and iii) biological complexity behind plankton system functioning.
\end{abstract}

Key words: Plankton; ecology; evolution; coastal ecosystems; biocomplexity.

Received: November 2017. Accepted: December 2017.

\section{INTRODUCTION}

Multiple and intersecting evolutionary processes are at the base of assembly and functioning of ecological communities (Hendry, 2016). The latter are complex entities including populations of species whose ecological roles stem from several overlapping natural history processes, in which casualties and environmental constraints play simultaneously (Gould, 2002; Koonin, 2011). Understanding the evolutionary history of species, the possible drivers of species life-histories, the ecological benefit of inter-specific interactions and, ultimately, evolutionary processes behind biodiversity are of pivotal importance for ecosystem studies (Levin, 2007; Hendry, 2016).

Conceptual and methodological approaches intersecting ecology and evolution are frequently applied to study plankton, a community of rapidly evolving and strongly interconnected species including both unicellular and multicellular organisms (Lima-Mendez et al., 2015; D'Alelio et al., 2016a). The huge genetic diversity of plankton provides a molecular basis to an overwhelming phenotypic variability (de Vargas et al., 2015; Sunagawa et al., 2015). For instance: plankton individual-sizes span three orders of magnitude (Boyce et al., 2015); morphological characteristics, like surface-to-volume ratio, are extremely variable even within a single aquatic system
(Morabito et al., 2007); coloniality is wide-spread among distantly related phyla (e.g., from diatoms to pelagic tunicates; Bone and others, 1998; Seckbach and Kociolek, 2011); mixotrophy, or the contemporary presence of heterotrophic and autotrophic metabolism within the same organism, is common in planktonic protists (Stoecker et al., 2017); several intersecting trophic interactions may establish among plankters (D'Alelio et al., 2016b); and, ultimately, the overall diversity hardly fits into few functional groups (Hofmann, 2010; Flynn et al., 2012; Roselli et al., 2017).

Plankton play a key role in aquatic ecosystems, being at the base of food-webs and driving biogeochemical cycles, and are experimenting strong perturbations apparently connected to anthropogenic factors, but the fine-scale ecological mechanisms at the base of such phenomena are not fully understood (Behrenfeld and Boss, 2013; Hutchins and $\mathrm{Fu}, 2017$; Steinberg and Landry, 2017). In this context, 'eco-evo' approaches, being mainly focused on time (the main dimension of evolution), would be suitable to investigate cause-effect relationships within the wide array of potentially inter-dependent ecological phenomena. Long Term Ecological Research (LTER), consisting in sampling and analysing physical, chemical and biological variables at fixed sampling sites, with high time-frequency (e.g., weekly), and in the long term (decades), can represent profiting case studies to this re- 
spect (Hughes et al., 2017). By means of LTER-based systems ecology analyses, integrating fine-scale biological complexity and biogeochemical processes at ecosystem level, reductionist and holistic approaches congregate, allowing to 'uncovering the processes hidden because they occur slowly or because effects lag years behind causes' (Magnuson, 1990).

This paper takes the three-decades plankton LTER 'MareChiara' (LTER-MC) in the Gulf of Naples (Mediterranean Sea, Italy, Fig. 1; Ribera d'Alcalà et al., 2004) as a benchmark for new-generation LTER-based eco-evo studies. This latter approach is far more important in light of: i) the observed fast adaptation of planktonic microbes to global change; ii) the rising impact of the latter on fishery-dependent human societies and iii) the under-exploitation of LTER studies in marine policy (Barange et al., 2014; Irwin et al., 2015; Hughes et al., 2017; Hutchins and Fu, 2017). Based on studies carried out in the Gulf of Naples (GoN) and published mostly within the last ten years into ISI journals, I herein examine: i) the evolutionary bases to plankton biodiversity (i.e., the founding property of both species and community adaptive potential); ii) the ecological and evolutionary determinants of population and community dynamics; and iii) the suitability of holistic LTER-based eco-evo approaches towards understanding the biological mechanisms behind systemic response of plankton to environmental variability.
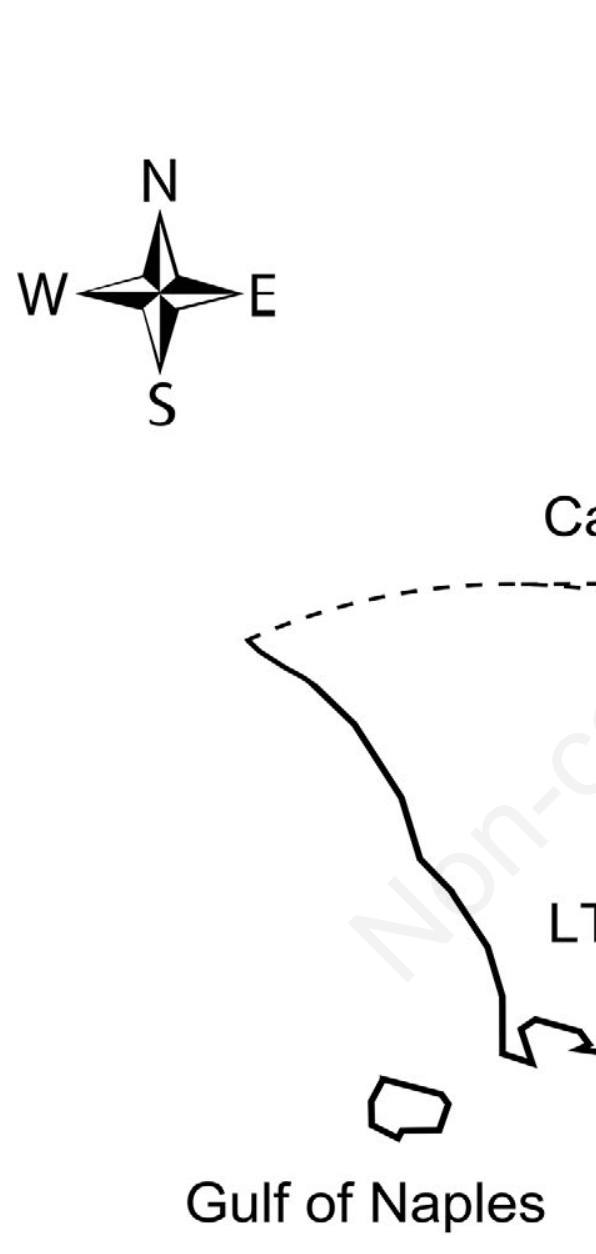

\section{Tyrrhenian Sea}

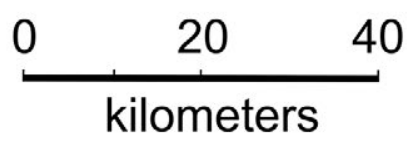

Fig. 1. Map of the Gulf of Naples (Thyrrenean Sea, Mediterranean Sea, Italy) and geographic position of the Long Term Ecological Research station MareChiara (LTER-MC). 


\section{EVOLUTIONARY COMPLEXITY BEHIND DIVERSITY}

The huge species diversity shown by plankton intrigues ecologists since decades. Why does competitive exclusion (i.e., the dominance of few fitter species) does not apply within an unstructured, homogeneous environment like the planktonic one is the main issue introduced by the renowned paper 'The paradox of the plankton' by Hutchinson (Hutchinson, 1961).

Experimental observations explicated the above-mentioned paradox by suggesting that stable coexistence of distinct species at the same trophic level is a probable outcome of resource-competition processes (Tilman 1976, 1977). In this context, more than 500 plankton taxa were identified in the GoN within thirty-three years of observation and most of them have apparently similar ecological roles (Mazzocchi et al., 2011; Piredda et al., 2017). Nowadays we now that a high functional redundancy at community level is not unusual in nature (Lefcheck et al., 2015), it can emerge even at stable environmental conditions, as reported in experimental evolution studies with microbes (Maharjan et al., 2007), and its main ecological role is to guarantee the survival of functional groups in case of species extinctions (Rosenfeld, 2002).

Protists (i.e., unicellular eukaryotes) are the main contributors to plankton metagenome (de Vargas et al., 2015; Sunagawa et al., 2015). Despite the dominance of fastreplicating and bloom-forming species, about $30 \%$ of planktonic protist diversity in the oceans is assigned to rare taxa (i.e., whose abundances are less than $0.01 \%$ of the total abundance) and the latter can contribute up to $16 \%$ of coastal phytoplankton biomass (Ignatiades and Gotsis-Skretas, 2013; de Vargas et al., 2015). Both blooming and non-blooming species can be present within the same community and at the same time in coastal plankton systems such as the GoN (Ribera d'Alcalà et al., 2004). These data are in line with the observation that a myriad of species in nature are rare (have either low reproductive or high turnover rates) but they are anyway ecologically successful and determinant in community functioning (Jain et al., 2014). While the role of the rarest is still not clear in marine plankton, it has been suggested that freshwater ecosystems' resilience is strongly linked with the presence of rare phytoplankton taxa (Downing and Leibold, 2010).

Most evolutionary models based on the classic 'fitness landscape' conceptual scheme (Wright 1932) and exploiting experimental evolution indicate that microbial species emerge by the divergence of lineages due to differential adaptation to distinct environmental conditions (De Visser and Krug, 2014). In the above-mentioned model, the fittest clonal lineages are advantaged in respect to 'flattest' ones, i.e., those having lower abundance and ecological specialization. Such 'adaptive' dynamics can be found in data generated by culture-based experimental evolution and genomics involving planktonic protists (Lohbeck et al., 2012; Mock et al., 2017) and plausibly represents the mechanism behind the fast adaptation of phytoplankton to global change, which is particularly relevant for blooming species (Irwin et al., 2015).

Yet, the above-mentioned 'fitness model' apparently does not fit in real frequency-distributions pertaining planktonic protists. Some other computational evolutionary-models assess that 'fittest' and 'flattest' clonal lineages can alternate in dependence of vegetative growth and evolutionary rates (Wilke et al., 2001) (Fig. 2). Namely: i) the fittest emerge at lower mutation and higher replication rates, when rarer positive mutations produce genotype-clouds whose frequency distributes around narrow fitness peaks, while purifying selection sharpens distribution shoulders (Wilke et al., 2001); ii) by contrast, the flattest emerge at higher mutation and lower replication rates, when more frequent positive mutations produce genetic clouds including a higher number of slightly different and evenly represented genotypes whose abundances distribute around 'mutationally robust' flatter peaks (Wilke et al., 2001).

In this context, metabarcoding suggests that protist diversity in the GoN is higher during winter, i.e., the nonblooming season, when virtually all detected species are rare and blooms are of lower intensity than in other seasons (Piredda et al., 2017). By combining the 'flatness model' mentioned above with time-repeated biodiversity explorations carried out at LTER-MC, one can depict a possible scenario behind the dominance of the flattest during winter non-blooming phases in the $\mathrm{GoN}$, a pattern that is explainable with few conceptual steps:

- The lower amount of nutrients in the photic zone during winter promotes growth of protist groups with higher surface-to-volume ratios and, thus, higher efficiencies in nutrient-uptake, such as flagellates (Zingone et al., 2009; Edwards et al., 2013);

- While stronger in some characters, selection may be relaxed in other ones, thus leaving room to intra-group genetic divergence and producing flat but 'rugged' fitness landscapes not necessarily determined by differential adaptation (Koonin, 2011);

- In relation with the latter point, despite a common cell shape, (dino)flagellates show high inter- and intra-specific diversity (Gribble and Anderson, 2007; Murray et al., 2012), which can correspond to potentially functional diversity, such as that present in the production of secondary metabolites (Murray et al., 2012).

In addition to the simple scenario depicted above, one must consider that even short-term environmental variability strongly contributes in shaping diversity within communities of planktonic protists. For instance, the fre- 
quent alternations between coastal and offshore waters occurring in the GoN during summer, known as 'green-blue swings', are a determinant factor for diversity conservation (Cianelli et al. 2017; D'Alelio et al., 2015): by exerting a so-called 'intermediate disturbance' (sensu Reynolds et al., 1993), green-blue swings dilute the abundance of opportunistic (most abundant) species and promote survival of the rarest ones (Cianelli et al., 2017). In addition, according with integrative studies on microbes coupling experiments and modelling, the fitter-flatter species coexistence emerges within the same environment when copious trade-offs between potentially different strategies establish due to fine-scale environmental variability (Beardmore et al., 2011).

\section{LIFE-CYCLE DRIVEN EVOLUTIONARY COMPLEXITY}

Functional diversity can also evolve by chance (Gould, 2002; Koonin, 2011). An example to this respect is exaptation, which occurs when phenotypic traits apparently selected for a specific function assume a different and more determinant role in the course of species' evolutionary history (Gould and Vrba, 1982). To this respect, adaptation to stochastic environmental factors could be largely dependent from evolvability, or, the capability of a population to generate diversity, enhance the standing genetic variation and develop adaptive solutions (Koonin, 2011 and reference therein).

Evolvability is promoted by the interplay between stochastic biological processes, such as genetic mutation and recombination (Koonin, 2011). Though conceptually robust, the evolutionary models presented in the previous section do not contemplate homologous genetic recombination, i.e., the exchange of pieces between two similar or identical DNA molecules, which constitute an important mechanism of genetic diversification in planktonic prokaryotes and protists (D'Alelio and Gandolfi, 2012; Rengefors et al., 2017). As for planktonic cyanobacteria, genetic mutation and recombination occur at the same rate in the micro-evolution of the freshwater genus Planktothrix, but recombination can introduce double more diversity than mutation (D'Alelio et al., 2013) and also promote adaptive evolution (Tooming-Klunderud et al., 2013).

Concerning protists, many of which have a sexual re-

\section{Lower mutation rate Higher replication rate

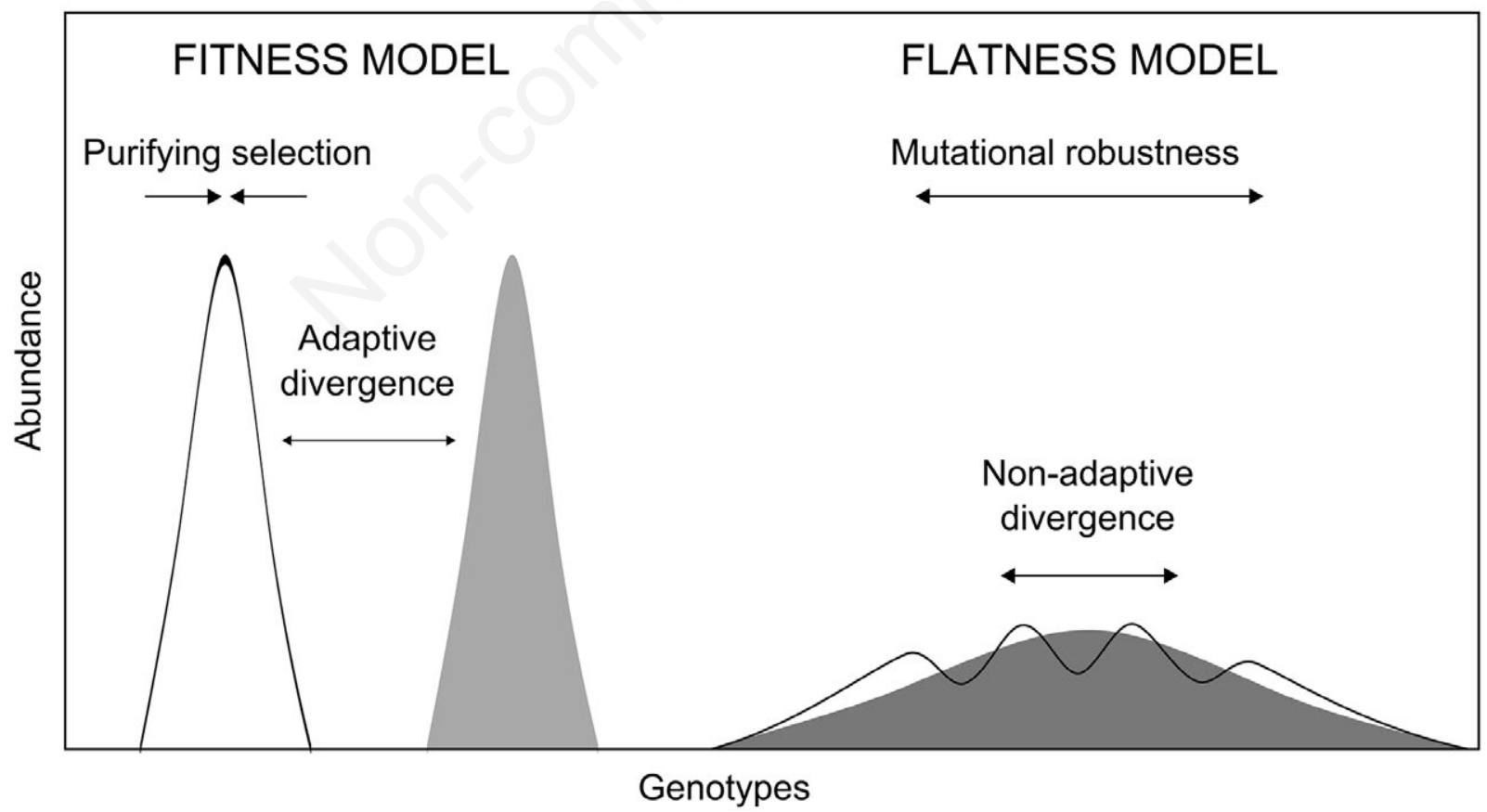

Fig. 2. Schematic of evolutionary landscapes (sensu Wright 1932) representing evolutionary models potentially applicable to planktonic protists based on observations published by Wilke et al. (2001). Curves are frequency-distributions for genotypes within different populations. Full-grey curves refer to populations at initial conditions (before divergence), empty-black curves refer to populations diverging from those present at initial conditions. 
production, recombination occurs with meiosis during gametogenesis (Rengefors et al., 2017). In many species, sexual processes are deeply tangled within life-cycles and affect population survival (von Dassow and Montresor, 2010): this suggests that protist sex is definitely not an evolutionary relict but an acquired strategy with eco-evolutionary implications, both proximate (lineage survival) and ultimate (generating diversity) (Speijer et al., 2015). In dinoflagellates, meiosis leads to the production of resting cysts, which are haploid life-cycle stages capable to resist at the sea bottom, so to guarantee survival over longer periods of deprived environmental conditions (von Dassow and Montresor, 2010). In most diatoms, sex is necessary to generate larger-size cells, thus counteracting the progressive cell-size decrease occurring at each vegetative division and bringing asexual clonal-lineages to death (Montresor et al., 2016).

The easily-culturable species within the diatom Pseudo-nitzschia represent good study-systems in sorting for the role of sex in diatom evolution. For instance, despite the high mutation frequency associated to the dominance of vegetative reproduction (D'Alelio et al., 2009a; Tesson et al., 2013), periodic sexual events provide species with a cohesive genetic-force that limits intraspecific genetic divergence and promotes species maintenance (Amato et al., 2007; D'Alelio et al., 2009a). In addition, sex can also occur between different species, leading to hybrid speciation (Amato and Orsini, 2015; D'Alelio and Ruggiero, 2015).

Long-term population genetics of $P$. multistriata in the GoN indicated that planktonic diatoms can produce the same level of diversity (say, genotypic richness) by means of either genetic mutation or recombination (Ruggiero et $a l$, in press). In the above-mentioned species, the highest genetic differentiation occurs in the course of apparently infrequent 'clonal expansions' establishing when blooms are flanked by a temporary but strong restriction of sex , which determines a positive unbalance of the mutationto-recombination ratio (Ruggiero et al., in press) (Fig. 3). Clonal expansions are ephemeral but massive processes ending with a 'survival of the fittest' dynamics that determines a sharp decrease in genotypic richness and the dominance of a 'super-genotype', which produces a 'quasi-monoclonal bloom' that follows a 'multi-clonal' one (Ruggiero et al., in press) (Fig. 3).

Similar dynamics are also observed in 'epidemic' bio-

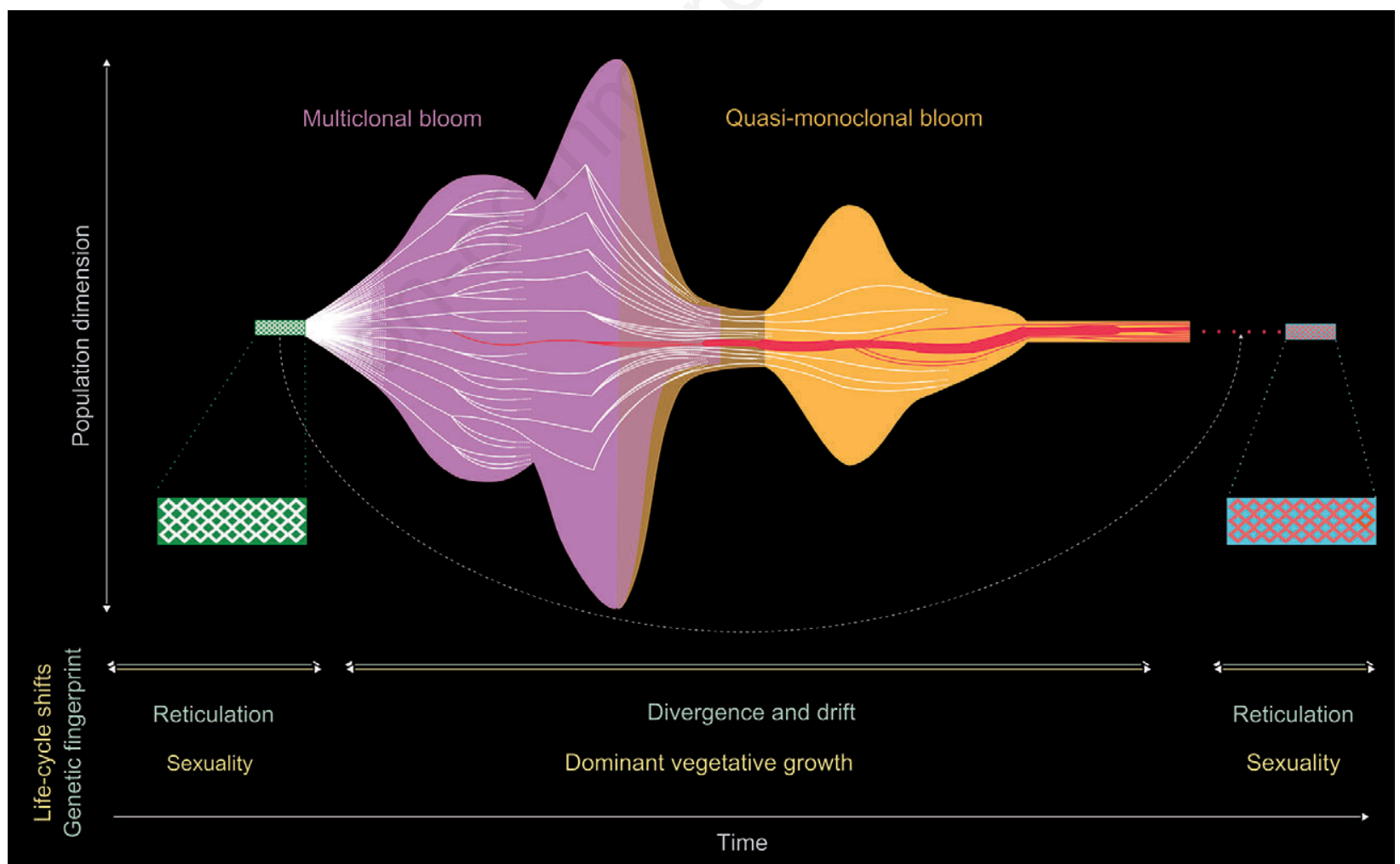

Fig. 3. Schematic of a clonal expansion in a planktonic protist, modified from Ruggiero et al. (in press). White lines are genotypes undergoing clonal divergence (lines' bifurcation), the red line represents a successful genotype emerged in the course of a clonal expansion. Reticulated patterns indicate the combined action of genetic divergence (mutation) and convergence (recombination). Dotted white and red lines indicate a possible pathway of recombination between white and red lineages after the bloom of the latter. 
logical systems, such as pathogenic bacteria and protozoans, in which clonal expansions are generally linked to strong selection over fitter recombinant genotypes operated by favourable environmental conditions (Maynard Smith et al., 1993; Tibayrenc and Ayala, 2012). The clonal expansion detected in P. multistriata was apparently generated by the presence, in the blooming population, of a single mating type, which was therefore unable to undergo sex: the dominance of a 'super-genotype' was plausibly determined by life-cycle characteristics as well as by environmental selection (Ruggiero et al., in press). The 'evolutionary jump' gathered by P. multistriata via clonal expansion made the population dramatically change its genetic fingerprint when the dominant genotype finally recombined with more distantly related ones (Ruggiero et al., in press) (Fig. 3).

\section{MICROEVOLUTIONARY BASES OF POPULATION DYNAMICS}

Whereas evolutionary complexity sustains species evolution, diversification processes occurring at population level (i.e., microevolution) promote species adaptation to local conditions. Although plankton species' populations are characterized by a high temporal and spatial intermittency (Martin et al., 2005; Cloern and Jassby, 2010), periodic seasonal blooms are observed at both local and global scales (Ruggiero et al., 2015; Boyce et al., 2017), suggesting that adaptive processes are at the base of the phenology observed.

In confined aquatic systems, such as freshwater lakes, blooms of planktonic cyanobacteria can be reliably linked to evolutionary adaptation (D'Alelio et al., 2011): specifically, populations of Planktothrix rubescens living in deeper lakes evolved more robust gas-vesicles (i.e., capable to resist stronger water-pressures during lake overturns) than populations living in shallower lakes, and this 'differential selection' led distinct populations to float and bloom in the surface photic zone of lakes with different maximum depths. Analogous studies have not been performed on planktonic protists, for the lack of reliable molecular resources (i.e., background description of functional loci) that allow tracking differential selection by means of 'simpler' population genetics approaches. Nonetheless, population genetics focused on neutrally evolving genes, when coupled with life-history investigations, can provide insights into those microevolutionary processes occurring at species level and potentially affecting population dynamics (Ruggiero et al., in press). This latter integration can be more likely obtained in LTER investigations.

Biologically regulated life-history processes (such as timing of recruitment of new individuals) are factors reinforcing ecological specialization in general (Poisot et al., 2011). Among unicellular plankton, diatoms show highly organized life cycles, with a biological clock that regulates the emergence of sex and periodical recruitment of sexual generations (Montresor et al., 2016). In the GoN, a population of the diatom $P$. multistriata observed for ten consecutive years underwent sex with a tight biennial periodicity, with two consecutive sexual events separated by about 50 mitotic generations (D'Alelio et al., 2010). This biological clock was apparently regulated by cell-size, since sex occurred in cells below a threshold size reached after a precise number of vegetative divisions (D'Alelio et al., 2009b).

Considering planktonic diatoms as model systems for intersecting evolutionary and ecological processes at population level, one may speculate that clonal expansions as that mentioned in the former section can lead to the fast evolution of genotypes particularly adapted to specific environmental conditions, or ecotypes, which can potentially turn into ecological species. Based on population biology (genetics and demography) and modelling observations, a possible coupled microevolutionary/life-history dynamics at the base of ecological specialization in the genus Pseudo-nitzschia can be drawn as follows:

- A cloud of closely related genotypes emerges from a clonal expansion (i.e., a bloom including only closelyrelated genotypes) and constitutes a potential new ecotype (Ruggiero et al., in press);

- Sex occurs at the end of this bloom, when i) encounter between mating cells is favoured by higher population density (D'Alelio et al., 2009b) and ii) gametogenesis is energetically affordable because vegetative growth has stopped (Scalco et al., 2014);

- The sexual progeny enters a precise life-cycle periodicity with sex limited to the blooming season that generated it (D'Alelio et al., 2010);

- The phasing of bloom and sex promotes breeding and recombination within and not between different ecotypes, thus guaranteeing the maintenance of selected genetic features.

Since the timing of diatom sex is biologically determined, an ecotype may phase its life cycles with the periodicity of seasonally-determined environmental constraints, thus contributing to the emergence of seasonality. For instance, it has been observed that species in the genus Pseudo-nitzschia tend to form blooms during different seasons within the same coastal system (Ruggiero et al., 2015) and an incipient ecological speciation, apparently driven by sexual isolation between differently occurring morphotypes, has been observed in P. galaxiae (Cerino et al., 2005).

The accumulation, generation after generation, of life history processes (such as genetic differentiation, differential adaptation and life-cycle shifts) plausibly provided bases to emergence of seasonality of different plankton 
groups in coastal systems like the GoN (Modigh, 2001; Ribera d'Alcalà et al., 2004; Zingone et al., 2009; Mazzocchi et al., 2011; Ruggiero et al., 2015; Piredda et al., 2017). Nonetheless, phenology is subordinated to the ability of species populations to overcome short-term variabilities stemming from the tangled interplay of proximate biological and physical factors whose relative strengths can change seasonally (Smayda, 1980; Reynolds, 1984; Wyatt, 2014).

Recent advances in disentangling biological from physical drivers of plankton dynamics at short-time scale have been gathered by integrating oceanographic and ecological observations with modelling (Cianelli et al. 2017). The application of these techniques to plankton in the coastal GoN revealed that the dynamics of species abundances in coastal water masses is mainly ruled by biological factors, such as i) highly plastic physiological-responses of phytoplankton to short-term environmental variability, ii) biologically-regulated germination and formation of resting stages involving (fitter) species producing massive blooms (Montresor et al., 2013), and iii) inter-specific interactions, involving mainly non-blooming (flatter) species (Cianelli et al. 2017). All these factors ultimately determine species succession at homogeneous environmental conditions (Scheffer et al., 2003).

\section{FROM EVOLUTIONARY TO SYSTEMS ECOLOGY}

Ecological communities are complex adaptive entities in which both direct and indirect inter-specific interactions shape the coevolution of complementary traits that promote community stability (Joppa et al., 2009; Turcotte et al., 2012; Guimarães et al., 2017). Despite most studies (including those mentioned in the previous sections) consider single species populations in a simplified context ruled by genetic and environmental constraints, plankton species are not mutually isolated in the environment, their populations are continuously mixed one another and several kinds of interactions can establish and affect both population and community dynamics (Lima-Mendez et al., 2015; D'Alelio et al., 2016a).

Coevolution of plankton organisms has been mainly put in relation to mutualistic and antagonistic interactions, such as symbiosis and parasitism, which seem to be widespread in the oceans and play an important role in global biogeochemical cycles (Lima-Mendez et al., 2015; Guidi et al., 2016). Nonetheless, other trophic relationships can emerge from complex natural history processes in which predators and preys reciprocally affect each other's evolution. For instance, the pelagic tunicate Oikopleura dioica (Appendicularia) is capable of 'breeding' the ciliate Strombidium spp. with plankton particles directed by feeding currents towards the tunicate's gelatinous 'house'
(Lombard et al., 2010); therefore, when its esophagus has grown enough to ingest larger particles, the same appendicularian feeds on ciliate cells, which are energetically richer than small-sized phytoplankton (Lombard et al., 2010). Remarkably, parasitism, mutualism and predatorprey relationship succeed in time in the course of a single life-history (Lombard et al., 2010).

Ciliate-appendicularian coevolution apparently emerged from the mutual ecological benefit of establishing a trophic interaction: namely, ciliates provide appendicularians with an essential, additional food-supply and, at the same time, take advantage of appendicularian houses to survive and grow in food-limited environments (Lombard et al., 2010). Furthermore, this evolutionarydetermined ecological strategy has important implications in the functioning of the pelagic system, since appendicularians and ciliates play an important position in plankton food-web (D'Alelio et al., 2016a). While appendicularians are important hubs (i.e., they up-take and deliver a remarkable amount of organic matter within the plankton food-web) and act as keystone species (sensu Power et al., 1996), ciliates are important food-sources for copepods in oligotrophic conditions, because they deliver to these latter animals organic matter which they cannot directly eat, such as the smaller-sized picoplankton (D'Alelio et al., 2016a).

\section{INTERACTION-BASED PLANKTON FUNCTIONING}

Plankton are considered as 'complex adaptive systems' (Leibold and Norberg, 2004), in which low-level interactions, i.e., between individuals and the environment and among individuals, determine high-level collective responses (Levin, 2007). Therefore, investigating shortterm system-responses can provide us with conceptual bases to delineate the self-organization/regulation abilities of plankton communities. To the latter respect, the coastal plankton in the GoN, which lives within an instable environment at the boundary between the coastal, eutrophic, and offshore, oligotrophic, dominions, can represent a suitable model system (Ribera d'Alcalà et al., 2004; D'Alelio et al., 2015).

In the GoN, a study comparing community dynamics from nanoflagellate to predatory mesozooplankton (within an individual size-range spanning $5-2 \cdot 10^{3} \mu \mathrm{m}$ ) indicated the presence of co-variations of species trends potentially related to different trophic links (D'Alelio et al., 2015). When assembled into networks, co-variation links help identifying system responses to a level higher than that of population dynamics (Loreau, 2010). For instance, the association network referring to a seasonal plankton community in the GoN displayed a vertical topology (i.e., phytoplankton $=>$ herbivore zooplankton $=>$ carnivore 
zooplankton) during coastal, eutrophic states and a more scattered topology (dominated by links among microbes) during offshore, oligotrophic states (D'Alelio et al., 2015). The above-mentioned study suggested that:

- The effects of resource intermittency may propagate at different levels of ecological complexity (from individuals to individuals' interactions);

- The community may respond 'adaptively' to physicalchemical changes, like oscillations between eu- and oligotrophy;

- Biological diversity would be crucial to guarantee a system-response driven by changes in trophic interactions within the same community.

Biodiversity is thought to enhance trophic diversity within ecosystems (Lefcheck et al., 2015), and, in turn, the stability of the latter depends from the robustness of ecological networks regulated by trophic interactions (Barabás et al., 2017). Studying food-webs is thus fundamental to reconcile the biodiversity (how many species are there), structure (how they relate reciprocally) and functioning (what they do collectively) in ecosystems (Thompson et al., 2012). Also, ecological network models exploiting the Ecopath methodology (i.e., interpolating ecological networks by modelling biomass flows into ecosystems) are among the best tools to this purpose (Barabás et al., 2017). Building on qualitative observations carried out in the GoN, the plankton community was investigated with one of such models (D'Alelio et al., 2015, 2016a, 2016b), in which:

- 'Diversity' was defined by the variety of 'functional web-nodes', i.e., species or groups of organisms with specific biological characteristics (namely, size, physiology, metabolism, behaviour and diet);

- 'Structure' was defined by the topology of food-weblinks, i.e., overall direction and intensity of biomass fluxes among web-nodes (derived iteratively by the model based on nodes' biomass and biological characteristics);

- 'Functioning' was defined as the efficiency of fluxes (across the web and between consecutive trophic levels) that was estimated from model output.

The above-mentioned model reproduced a plankton food-web including very few specialists, which limited interspecific competition, and a huge amount of weak trophic links, which increased trophic alternatives (Fig. 4). In virtue of these properties, almost all species in the plankton food-web could switch their trophic preferences based on available resources (Fig. 4). The above-mentioned study indicated that, when integrated within a foodweb context, evolutionary determined ecological strategies were crucial to drive system functionality (D'Alelio et al., 2016a):

- Firstly, nested and convoluted protozoan-metazoan interactions involved a myriad of trophic strategies (such as mixotrophy, niche partitioning among protozooplankters and different selective feeding by mesozooplankton) establishing several potential trophic pathways;

- The above-mentioned trophic step showed the highest trophic efficiency (up to $25 \%$ ), the latter being the ratio between the biomass taken by a trophic level and that delivered to the subsequent one;

- High efficiency at intermediate trophic steps allowed smoothing the effects of oscillations in primary production on planktivorous-fish production;

- Finally, the surplus of matter and energy available at the lower levels of the web was used by protozooplankton as a resource to maintain species diversity.

Trophic plasticity at organismal level determines ecological network flexibility, expressed as modifications in both direction and intensity of trophic links (Fig. 4): this allows plankton food-web to respond adaptively to system changes. Such mechanism can explain the high resilience of mesozooplankton grazers to trophic intermittency reported in the GoN (Mazzocchi et al., 2012) (D'Alelio et al., 2016a).

\section{CONCLUDING REMARKS}

Important modifications are presently occurring in marine plankton communities - e.g., the rise of Harmful Algal Blooms and global decrease of both phyto- and zooplankton biomasses (Boyce et al., 2010; Chust et al., 2014; Glibert and Burford, 2017). These phenomena are plausibly the result of complex feedback mechanisms determined by interplaying biological and environmental factors, such as fast adaptation of microbes to changes in chemical-resources regimes and trophic cascades occurring at food-web level.

Despite the rising of reductionist evolutionary-ecology approaches (mainly focusing on phytoplankton experimental evolution and population dynamics; e.g., Collins et al., 2014 and references therein), holistic 'systems ecology' approaches that explicitly consider species interactions in the process of understanding of plankton functioning and resilience to environmental changes are still at their infancy (Stec et al., 2017). Indeed, studying ecosystems from a time-based, evolutionary perspective relies on the availability of data over a time-period that is suitable to observing processes that occur at very different time scales but are all interconnected.

In Fig. 5 the main cause-effects relationships playing in plankton function discussed in the present paper have been assembled. Being based on patterns observed and processes identified in the GoN, some links in the abovementioned network were not discussed though, such as the effects of genetic diversity on reproduction rates and of environmental factors on population dynamics and 


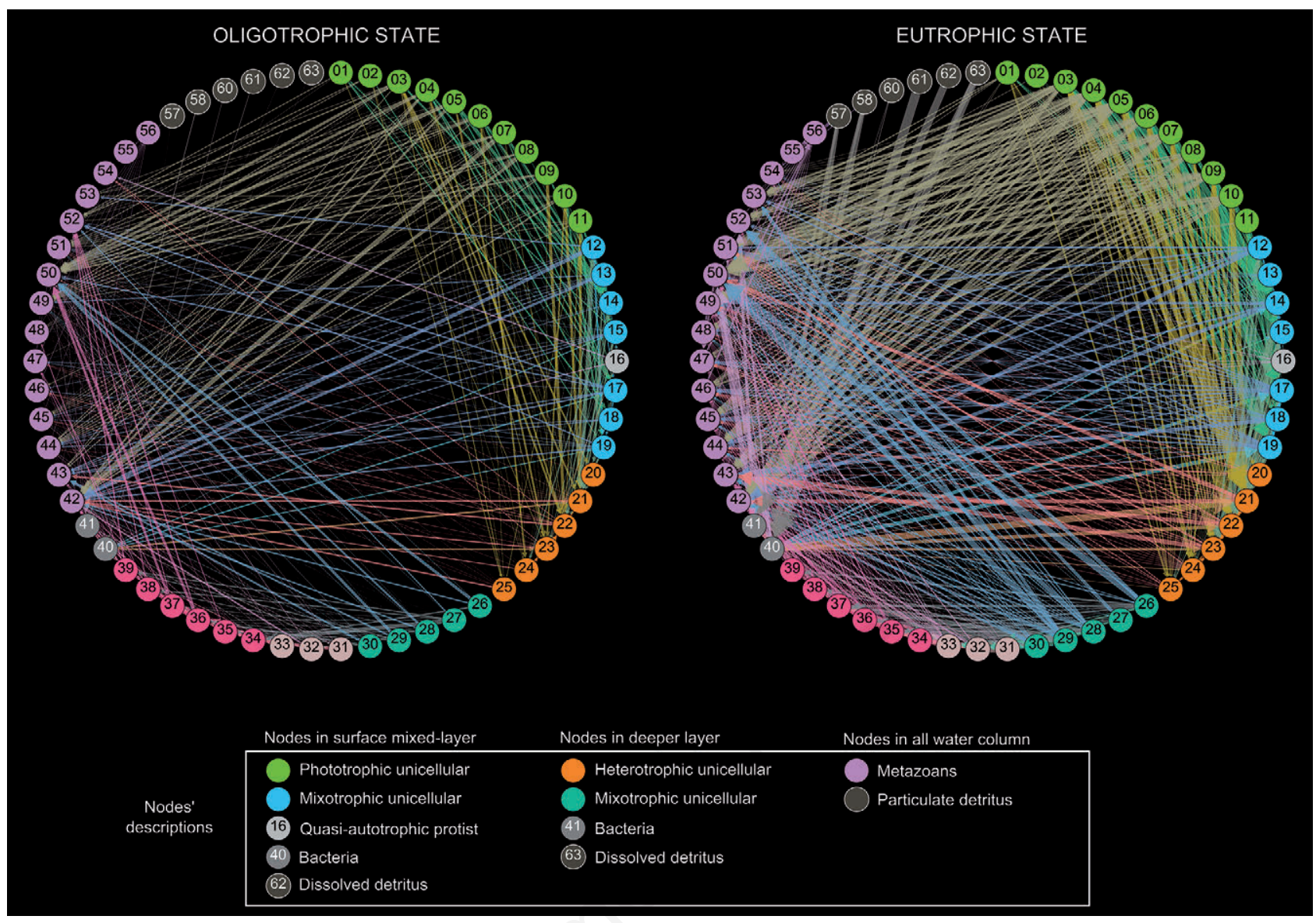

Fig. 4. Schematic of the plankton food-web in the Gulf of Naples during oligotrophic and eutrophic states, modified from D'Alelio et al. (2016a). Nodes are species or group of species; links are biomass fluxes. In order to enhance data visualization, web links have been obtained from log-transformation of fluxes-data presented in D'Alelio et al. (2016a).

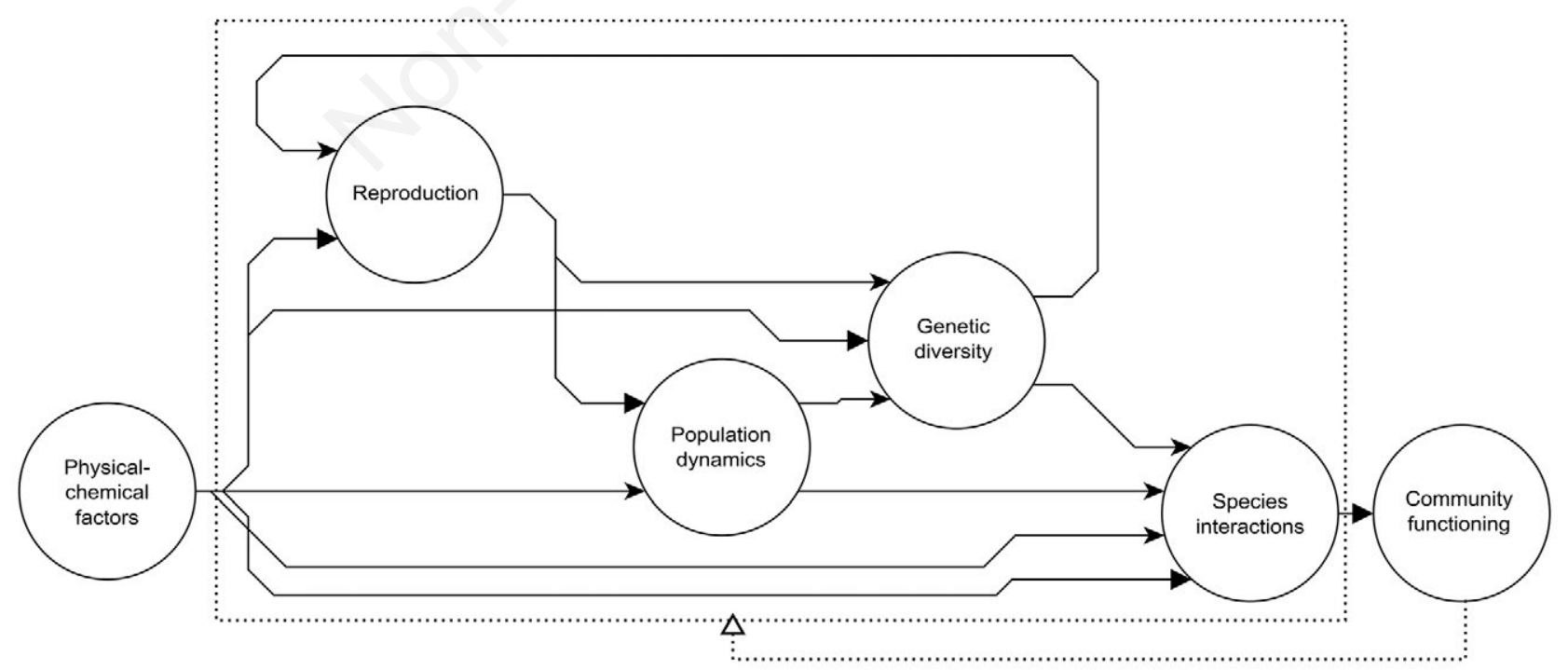

Fig. 5. Hierarchical network schematizing the main regulative mechanisms of plankton system functioning based on considerations presented in this paper. Full and dotted arrows illustrate direct and indirect links, respectively. The dotted square includes community properties indirectly affected by community functioning. 
inter-specific interactions (for a review, see D'Alelio et $a l ., 2016 \mathrm{~b}$ and references therein). One must anyway consider that biocomplexity in the plankton system largely exceeds that considered in the present paper.

As for evolutionary complexity and its role in species adaptation, microevolutionary models discussed herein can be likely applied to asexually reproducing planktonic animals (e.g., cladocerans and pelagic tunicates) in the need of interpreting their adaptation dynamics to changing environmental conditions. Concerning ecological complexity, plankton food-web models should i) consider presently neglected organisms, such as virus and jellyfish, both playing fundamental roles in marine ecosystems (Boero, 2015; Lara et al., 2017), and ii) integrate also the benthos dominion, in light of frequent biologically-mediated interactions between the two systems (D'Alelio et al., 2017).

To this latter respect, LTERs offer a unique opportunity for investigating ecological and evolutionary determinants driving plankton functioning, from reproductive processes occurring at species level to the circulation of energy and matter playing at system level (Fig. 5). These researches can set important conceptual and methodological backgrounds to next-generation observatory studies exploiting meta-omics technologies (de Vargas et al., 2015; Sunagawa et al., 2015; Guidi et al., 2016) and exploring plankton biocomplexity and functioning over complete and time-resolved biological and physical data matrices.

\section{ACKNOWLEDGMENTS}

This work is dedicated to the memory of Dr. Giuseppe Morabito, a brilliant plankton ecologist as well as a great man. One anonymous reviewer is gratefully acknowledged for providing comments improving the quality of this work. The LTER-MC belongs to the national and international Long Term Ecological Research networks (LTER-Italy, LTER-Europe and ILTER). LTER-MC data generation and processing is entirely supported by the Stazione Zoologica Anton Dohrn, Naples. I thank the Flagship Project RITMARE - The Italian Research for the Sea - coordinated by the Italian National Research Council and funded by the Italian Ministry of Education, University and Research within the National Research Program 2011-2013.

\section{REFERENCES}

Amato A, Kooistra WHCF, Ghiron JHL, Mann DG, Pröschold T, Montresor M, 2007. Reproductive isolation among sympatric cryptic species in marine diatoms. Protist 158:193-207.

Amato A, Orsini L, 2015. Rare interspecific breeding in Pseudo-nitzschia (Bacillariophyceae). Phytotaxa 217:145.

Barabás G, Michalska-Smith MJ, Allesina S, 2017. Self-regulation and the stability of large ecological networks. Nat. Ecol. Evol.
Barange M, Merino G, Blanchard JL, Scholtens J, Harle J, Allison EH, et al., 2014. Impacts of climate change on marine ecosystem production in societies dependent on fisheries. Nat. Clim. Chang. 4:211-216.

Beardmore RE, Gudelj I, Lipson DA, Hurst LD, 2011. Metabolic trade-offs and the maintenance of the fittest and the flattest. Nature 472:342-346.

Behrenfeld MJ, Boss ES, 2013. Resurrecting the ecological underpinnings of ocean plankton Blooms. Ann. Rev. Mar. Sci. 1-28.

Boero F, 2015. The future of the Mediterranean Sea ecosystem: towards a different tomorrow. Rend. Lincei 26:3-12.

Bone Q, others, 1998. The biology of pelagic tunicates. Oxford University Press Oxford.

Boyce DG, Frank KT, Leggett WC, 2015. From mice to elephants: overturning the "one size fits all" paradigm in marine plankton food chains. Ecol. Lett. 18:504-515.

Boyce DG, Lewis MR, Worm B, 2010. Global phytoplankton decline over the past century. Nature 466:591-596.

Boyce DG, Petrie B, Frank KT, Worm B, Leggett WC, 2017. Environmental structuring of marine plankton phenology. Nat. Ecol. Evol. 1:1484.

Cerino F, Orsini L, Sarno D, Dell'Aversano C, Tartaglione L, Zingone A, 2005. The alternation of different morphotypes in the seasonal cycle of the toxic diatom Pseudo-nitzschia galaxiae. Harmful Algae 4:33-48.

Chust G, Allen JI, Bopp L, Schrum C, Holt J, Tsiaras K, et al., 2014. Biomass changes and trophic amplification of plankton in a warmer ocean. Glob. Chang. Biol. 20:2124-2139.

Cianelli D, D'Alelio D, Uttieri M, Sarno D, Zingone A, Zambianchi E, Ribera d'Alcalà M, 2017 Disentangling physical and biological drivers of phytoplankton dynamics in a coastal system. Sci. Rep. 7:1-15

Cloern JE, Jassby AD, 2010. Patterns and scales of phytoplankton variability in estuarine-coastal ecosystems. Estuaries and Coasts 33:230-241.

Collins S, Rost B, Rynearson TA, 2014. Evolutionary potential of marine phytoplankton under ocean acidification. Evol. Appl. 7:140-155.

D’Alelio D, Amato A, Kooistra WHCF, Procaccini G, Casotti R, Montresor M, 2009a. Internal transcribed spacer polymorphism in Pseudo-nitzschia multistriata (Bacillariophyceae) in the Gulf of Naples: recent divergence or intraspecific hybridization? Protist 160:9-20.

D'Alelio D, Amato A, Luedeking A, Montresor M, $2009 \mathrm{~b}$. Sexual and vegetative phases in the planktonic diatom Pseudo-nitzschia multistriata. Harmful Algae 8:225-232.

D'Alelio D, Gandolfi A, 2012. Recombination signals in the rpoC1 gene indicate gene-flow between Planktothrix (Cyanoprokaryota) species. J. Phycol. 48:1424-1432.

D'Alelio D, Gandolfi A, Boscaini A, Flaim G, Tolotti M, Salmaso N, 2011. Planktothrix populations in subalpine lakes: selection for strains with strong gas vesicles as a function of lake depth, morphometry and circulation. FreshwATER Biol. 56:1481-1493.

D'Alelio D, Libralato S, Wyatt T, Ribera d'Alcalà M, 2016 a. Ecological-network models link diversity, structure and function in the plankton food-web. Sci. Rep. 6:21806.

D’Alelio D, Luongo G, Di Capua I, 2017. Plankton food for benthic fish: de visu evidence of trophic interaction between rainbow wrasse (Coris julis) and pelagic tunicates (Pegea confoederata). Adv. Oceanogr. Limnol. 8:6973. 
D’Alelio D, Mazzocchi MG, Montresor M, Sarno D, Zingone A, Margiotta F, et al., 2015. The green - blue swing: plasticity of plankton food-webs in response to coastal oceanographic dynamics. Mar. Ecol. 36:1155-1170.

D'Alelio D, Montresor M, Mazzocchi MG, Margiotta F, Sarno D, Ribera d'Alcalà M, 2016b. Plankton food-webs: to what extent can they be simplified? Adv. Oceanogr. Limnol. 7:67-92.

D'Alelio D, Ribera d'Alcalà M, Dubroca L, Sarno D, Zingone A, Montresor M, 2010. The time for sex: a biennial life cycle in a marine planktonic diatom. Limnol. Oceanogr. 55:106114.

D'Alelio D, Ruggiero MV, 2015. Interspecific plastidial recombination in the diatom genus Pseudo-nitzschia. J. Phycol. 51:1024-1028

D'Alelio D, Salmaso N, Gandolfi A, 2013. Frequent recombination shapes the epidemic population structure of Planktothrix (Cyanoprokaryota) in Italian subalpine lakes. J. Phycol. 49:1107-1117.

de Vargas C, Audic S, Henry N, Decelle J, Mahé F, Logares R, et al., 2015. Eukaryotic plankton diversity in the sunlit ocean. Science 348:1-12.

de Visser JAG, Krug J, 2014. Empirical fitness landscapes and the predictability of evolution. Nat. Rev. Genet. 15:480-490.

Downing AMYL, Leibold MA, 2010. Species richness facilitates ecosystem resilience in aquatic food webs. Freshw. Biol. 55:2123-2137.

Edwards KF, Litchman E, Klausmeier CA, 2013. Functional traits explain phytoplankton community structure and seasonal dynamics in a marine ecosystem. Ecol. Lett. 16:56-63.

Flynn KJ, Stoecker DK, Mitra A, Raven JA, Glibert PM, Hansen PJ, Graneli E, Burkholder JM, 2012. Misuse of the phytoplankton-zooplankton dichotomy: the need to assign organisms as mixotrophs within plankton functional types. J. Plankton Res. 35:3-11.

Glibert PM, Burford MA, 2017. Globally changing nutrient loads and harmful algal blooms: Recent advances, new paradigms, and continuing challenges. Oceanography 30:58-69.

Gould SJ, 2002. The Structure of evolutionary theory. Harvard University Press, Harvard:1464 pp.

Gould SJ, Vrba ES, 1982. Exaptation-a missing term in the science of form. Paleobiology 8:4-15.

Gribble KE, Anderson DM, 2007. High intraindividual, intraspecific, and interspecific variability in large-subunit ribosomal DNA in the heterotrophic dinoflagellates Protoperidinium, Diplopsalis, and Preperidinium (Dinophyceae). Phycologia 46:315-324.

Guidi L, Chaffron S, Bittner L, Eveillard D, Larhlimi A, Roux S, et al., 2016. Plankton networks driving carbon export in the oligotrophic ocean. Nature 532:465-470

Guimarães PR, Pires MM, Jordano P, Bascompte J, Thompson $\mathrm{JN}, 2017$. Indirect effects drive coevolution in mutualistic networks. Nature 550:511-514.

Hendry AP, 2016. Eco-evolutionary dynamics. Princeton University Press: 416 pp.

Hofmann EE, 2010. Plankton functional group models - An assessment. Prog. Oceanogr. 84:16-19.

Hughes BB, Beas-Luna R, Barner AK, Brewitt K, Brumbaugh DR, Cerny-Chipman EB, et al., 2017. Long-term studies contribute disproportionately to ecology and policy. Bioscience 67:271-281.
Hutchins DA, Fu F, 2017. Microorganisms and ocean global change. Nat. Microbiol. 2: 201758.

Hutchinson G. E., 1961. The paradox of the plankton. Am. Nat. 95:137-145.

Ignatiades L, Gotsis-Skretas O, 2013. The contribution of rare species to coastal phytoplankton assemblages. Mar. Ecol. 35:132-145.

Irwin AJ, Finkel Z V, Müller-Karger FE, Troccoli Ghinaglia L, 2015. Phytoplankton adapt to changing ocean environments. P. Natl. Acad. Sci. USA 1-5.

Jain M, Flynn DFB, Prager CM, Hart GM, Devan CM, Ahrestani FS, et al., 2014. The importance of rare species: A trait-based assessment of rare species contributions to functional diversity and possible ecosystem function in tallgrass prairies. Ecol. Evol. 4:104-112.

Joppa LN, Bascompte J, Montoya JM, Solé R V, Sanderson J, Pimm SL, 2009. Reciprocal specialization in ecological networks. Ecol. Lett. 12:961-9.

Koonin E V, 2011. The logic of chance: the nature and origin of biological evolution. FT Press: 528 pp.

Lara E, Vaqué D, Sà EL, Boras JA, Gomes A, Borrull E, et al., 2017. Unveiling the role and life strategies of viruses from the surface to the dark ocean. Sci. Adv. 3:e1602565.

Lefcheck JS, Byrnes JEK, Isbell F, Gamfeldt L, Griffin JN, Eisenhauer N, et al., 2015. Biodiversity enhances ecosystem multifunctionality across trophic levels and habitats. Nat. Commun. 6:1-7.

Leibold MA, Norberg J, 2004. Biodiversity in metacommunities: Plankton as complex adaptive systems? Limnol. Oceanogr. 49:1278-1289.

Levin S, 2007. Fragile Dominion. Basic Books.

Lima-Mendez G, Faust K, Henry N, Decelle J, Colin S, Carcillo F, et al., 2015. Determinants of community structure in the global plankton interactome. Science 348:1-10.

Lohbeck KT, Riebesell U, Reusch TBH, 2012. Adaptive evolution of a key phytoplankton species to ocean acidification. Nat. Geosci. 5:346-351.

Lombard F, Eloire D, Gobet A, Stemmann L, Dolan JR, Sciandra A, Gorsky G, 2010. Experimental and modeling evidence of appendicularian-ciliate interactions. Limnol. Oceanogr. 55:77-90

Loreau M, 2010. From polutations to ecosystems: theoretical fondations for a new ecological synthesis. Princeton University Press: 320 pp.

Magnuson JJ, 1990. Long-Term Ecological Research and the invisible present. Bioscience 40:495-501.

Maharjan RP, Seeto S, Ferenci T, 2007. Divergence and redundancy of transport and metabolic rate-yield strategies in a single Escherichia coli population. J. Bacteriol. 189:2350-2358.

Martin AP, Zubkov M V, Burkill PH, Holland RJ, 2005. Extreme spatial variability in marine picoplankton and its consequences for interpreting Eulerian time-series. Biol. Lett. 1:366-369.

Maynard Smith J, Smith NH, O'Rourke M, Spratt BG, 1993. How clonal are bacteria? P. Natl. Acad. Sci. USA 90:4384-4388.

Mazzocchi MG, Dubroca L, García-Comas C, Capua I Di, Ribera d'Alcalà M, 2012. Stability and resilience in coastal copepod assemblages: the case of the Mediterranean longterm ecological research at Station MC (LTER-MC). Prog. Oceanogr. 97-100:135-151.

Mazzocchi MG, Licandro P, Dubroca L, Capua I Di, Saggiomo 
V, 2011. Zooplankton associations in a Mediterranean longterm time-series. J. Plankton Res. 33:1163-1181.

Mock T, Otillar RP, Strauss J, McMullan M, Paajanen P, Schmutz J, et al., 2017. Evolutionary genomics of the cold-adapted diatom Fragilariopsis cylindrus. Nature 541:536-540.

Modigh M, 2001. Seasonal variations of photosynthetic ciliates at a Mediterranean coastal site. Aquat. Microb. Ecol. 23:163-175.

Montresor M, Di Prisco C, Sarno D, Margiotta F, Zingone A, 2013. Diversity and germination patterns of diatom resting stages at a coastal Mediterranean site. Mar. Ecol. Prog. Ser. 484:79-95.

Montresor M, Vitale L, D'Alelio D, Ferrante MI, 2016. Sex in marine planktonic diatoms: insights and challenges. Perspect. Phycol. 3:61-75.

Morabito G, Oggioni A, Caravati E, Panzani P, 2007. Seasonal morphological plasticity of phytoplankton in Lago Maggiore (N. Italy). Hydrobiologia 578:47-57.

Murray SA, Garby T, Hoppenrath M, Neilan BA, 2012. Genetic diversity, morphological uniformity and polyketide production in dinoflagellates (amphidinium, dinoflagellata). PLoS One 7:1-14.

Piredda R, Tomasino MP, D’Erchia AM, Manzari C, Pesole G, Montresor M, et al., 2017. Diversity and temporal patterns of planktonic protist assemblages at a Mediterranean Long Term Ecological Research site. FEMS Microbiol. Ecol. 93:1-14.

Poisot T, Bever JD, Nemri A, Thrall PH, Hochberg ME, 2011. A conceptual framework for the evolution of ecological specialisation. Ecol. Lett. 14:841-851.

Power ME, Tilman D, Estes JA, Menge BA, Bond WJ, 1996. Challenges in the quest for keystones. Bioscience 46:609.

Rengefors K, Kremp A, Reusch TBH, Wood AM, 2017. Genetic diversity and evolution in eukaryotic phytoplankton: revelations from population genetic studies. J. Plankton Res. 0:1-15.

Reynolds CS, 1984. Phytoplankton periodicity: the interactions of form, function and environmental variability. Freshw. Biol. 14:111-142.

Reynolds CS, Padisák J, Sommer U, 1993. Intermediate disturbance in the ecology of phytoplankton and the maintenance of species diversity: a synthesis, p. 183-188 In: J. Padisák, CS Reynolds and U. Sommer (eds.), Intermediate disturbance hypothesis in phytoplankton ecology. Springer.

Ribera d'Alcalà $\mathrm{M}$, Conversano $\mathrm{F}$, Corato $\mathrm{F}$, Licandro $\mathrm{P}$, Mangoni O, Marino D, et al., 2004. Seasonal patterns in plankton communities in a pluriannual time series at a coastal Mediterranean site (Gulf of Naples): an attempt to discern recurrences and trends. Sci. Mar. 68:65-83.

Roselli L, Litchman E, Stanca E, Cozzoli F, Basset A, 2017. Individual trait variation in phytoplankton communities across multiple spatial scales. J. Plankton Res. 39:577-588.

Rosenfeld JS, 2002. Functional redundancy in ecology and conservation. Oikos 98:156-162.

Ruggiero MV, D’Alelio D, Ferrante MI, Santoro M, Vitale L, Procaccini G, Montresor M, 2017. Clonal expansion behind a marine diatom bloom. ISME J. doi: 10.1038/ismej. 2017.181. [Epub ahead of print].

Ruggiero MV, Sarno D, Barra L, Kooistra WHCF, Montresor M, Zingone A, 2015. Diversity and temporal pattern of Pseudo-nitzschia species (Bacillariophyceae) through the molecular lens. Harmful Algae 42:15-24.

Scalco E, Stec K, Iudicone D, Ferrante MI, Montresor M, 2014. The dynamics of sexual phase in the marine diatom Pseudo-nitzschia multistriata (Bacillariophyceae). J. Phycol. 50:817-828.

Scheffer M, Rinaldi S, Huisman J, Weissing FJ, 2003. Why plankton communities have no equilibrium: solutions to the paradox. Hydrobiologia 491:9-18.

Seckbach J, Kociolek P, 2011. The diatom world. Springer Science, Berlin: 534 pp.

Smayda TJ, 1980. Phytoplankton species succession, p. 493570. In: I. Morris (ed.), The Physiological ecology of phytoplankton. University of California Press, Berkeley

Speijer D, Lukeš J, Eliáš M, 2015. Sex is a ubiquitous, ancient, and inherent attribute of eukaryotic life. P. Natl. Acad. Sci. USA 112:8827-34.

Stec KF, Caputi L, Buttigieg PL, D’Alelio D, Ibarbalz FM, Sullivan MB, et al., 2017. Modelling plankton ecosystems in the meta-omics era. Are we ready? Mar. Genomics 32:117.

Steinberg DK, Landry MR, 2017. Zooplankton and the ocean carbon cycle. Ann. Rev. Mar. Sci. 9:413-444.

Stoecker DK, Hansen PJ, Caron DA, Mitra A, 2017. Mixotrophy in the marine plankton. Ann. Rev. Mar. Sci. 9:311-335.

Sunagawa S, Coelho LP, Chaffron S, Kultima JR, Labadie K, Salazar G, et al., 2015. Structure and function of the global ocean microbiome. Science 348:1-10.

Tesson SVM, Legrand C, Oosterhout C van, Montresor M, Kooistra WHCF, Procaccini G, 2013. Mendelian inheritance pattern and high mutation rates of microsatellite alleles in the diatom Pseudo-nitzschia multistriata. Protist 164:89-100.

Thompson RM, Brose U, Dunne JA, Hall RO, Hladyz S, Kitching RL et al., 2012. Food webs: reconciling the structure and function of biodiversity. Trends Ecol. Evol. 27:689-97.

Tibayrenc M, Ayala FJ, 2012. Reproductive clonality of pathogens: a perspective on pathogenic viruses, bacteria, fungi, and parasitic protozoa. P. Natl. Acad. Sci. USA 109:E3305-13.

Tilman D, 1976. Ecological competition between algae: experimental confirmation of resource-based competition theory. Science 192:463-465.

Tilman D, 1977. Resource competition between plankton algae: an experimental and theoretical approach. Ecology 58:338348.

Tooming-Klunderud A, Sogge H, Rounge TB, Nederbragt AJ, Lagesen K, Glöckner G, et al., 2013. From green to red: horizontal gene transfer of the phycoerythrin gene cluster between Planktothrix strains. Appl. Environ. Microbiol. 79:6803-6812.

Turcotte MM, Corrin MSC, Johnson MTJ, 2012. Adaptive evolution in ecological communities. PLoS Biol. 10:e1001332.

von Dassow P, Montresor M, 2010. Unveiling the mysteries of phytoplankton life cycles: patterns and opportunities behind complexity. J. Plankton Res. 33:3-12.

Wilke CO, Wang JL, Ofria C, Lenski RE, Adami C, 2001. Evolution of digital organisms at high mutation rates leads to survival of the flattest. Nature 412:331-333.

Wright S, 1932. The roles of mutation, inbreeding, crossbreeding and selection in evolution. Proceedings 6th Ann. Congr. of Genetics 1:356-366.

Wyatt T, 2014. Margalef's mandala and phytoplankton bloom strategies. Deep Sea Res. Part II Top. Stud. Oceanogr. 101:32-49.

Zingone A, Dubroca L, Iudicone D, Margiotta F, Corato F, Ribera d'Alcalà M, et al., 2009. Coastal Phytoplankton do not rest in winter. Estuaries Coasts 33:342-361. 